\title{
El docente como hacedor de didácticas
}

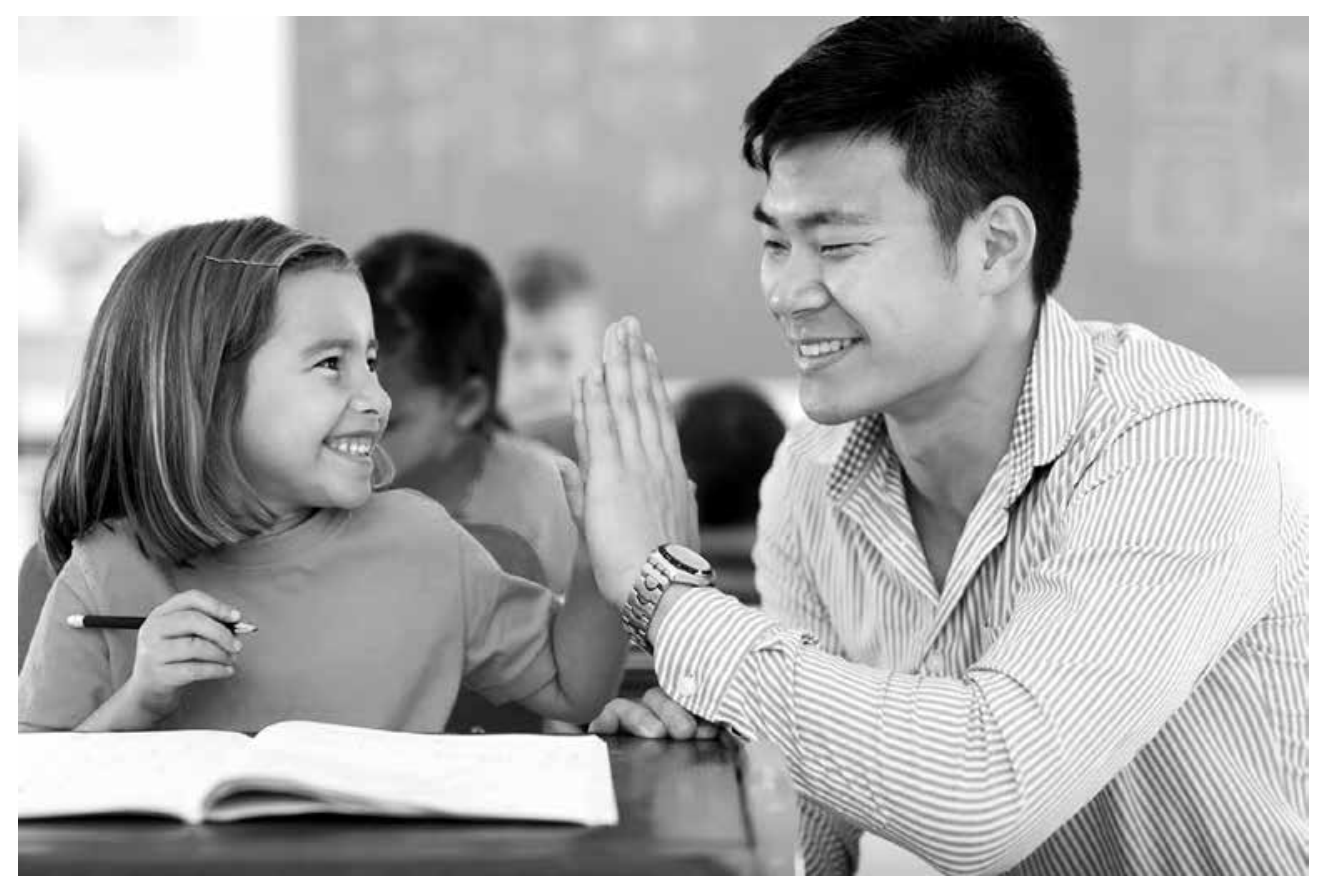

A lo largo de mi vida como docente me he preguntado constantemente sobre lo que significa ser un buen profesor. De un modo sencillo puedo compartir mis conclusiones: un docente es capaz de construir un puente entre la complejidad de sus lecturas previas acumuladas y sus preguntas compartidas con sus discípulos, camino de propiciar la reconstrucción de la pregunta desde cada uno (maestro y discípulo), hasta hacerlas suyas, hasta propiciar nuevos caminos en ellas, hasta promover la complicidad de las preguntas en aras de lograr un horizonte compartido. Esta comprensión del ser docente involucra tres dimensiones esenciales: el ser una persona buena (un ser humano bueno en términos morales y éticos), el saber a cabalidad la disciplina a compartir, el apropiarse de un tejido de formas capaces de dar cuenta de la comunicación entre su saber añejado por el ir y venir alrededor de tantas respuestas en diálogo permanente con la novedad de la pregunta desde sus estudiantes. Porque el verdadero saber no es la técnica ni la información compartida, es el modo como ese saber renace en el otro; por ello, la responsabilidad del docente respecto al fracaso del discípulo es altamente solidaria, siempre y cuando este asuma su compromiso por el encuentro de los tres: el maestro, el discípulo y la pregunta.

El problema de la educación hoy, desde sus complejas dimensiones, emerge como un prisma que revela los matices de los retos de la sociedad contemporánea. Las preguntas por el ser en sí y para sí (Sartre), las tensiones entre el habitus (Bourdieu) de cada individuo y las posibilidades de ocupar un lugar en el mundo, el mundo de 
la vida como tejido de razones comunicativas en ámbitos de otredad (Habermas), hacen de la escuela como institución el lugar axial de la vida en un mundo asfixiado de hipermodernidad (Lipovetsky). No obstante, la modernización (maquinización y técnica operativa) ha fragmentado al ser humano en sus relaciones y entornos, hasta límites extremos de alienación (Marx en los Manuscritos filosóficos ya se ocupaba de este hecho, incluso más allá del capitalismo). Los asomos de seres holísticos (aunque fuera una igualdad entre iguales también de élite) de Atenas y su devenir en una polis labrada por la palabra oral, la equidistancia discursiva y el deseo por hacer justicia han cedido a los extremos del individualismo, de la eficiencia y a una razón desbordada (aunque no haya otra forma de asumir todo este debate que desde los presupuestos mismos de la razón hemos construido hasta nuestros días).

En este devenir, los discursos se presentan traslapados en una emergencia, primero por el derecho a la vida y la integridad tanto física como mental del ser; hacia una necesidad de convivencia política capaz de garantizar en principio la vida, la libertad y, luego, los variados acuerdos sobre la propiedad a lo largo del tiempo (que arrastran procesos de construcción y destrucción de sentidos de justicia una vez instaurado el pacto político, en un debate que debe ser actualizado de un modo recurrente). Entonces, ya con vida y dentro de un pacto político, el modo como los individuos luchan por sus posibilidades materiales e intelectuales para ocupar un lugar en el mundo surge como una combinatoria entre las asignaciones naturales y socioeconómicas iniciales (en relación con la ausencia de una posición original rawlsiana de equidad plena), como insumos de la construcción de un sujeto pragmático ávido de acciones para apropiarse del tiempo y los recursos del mundo en relación con su ser y el desarrollo de sus actividades sociales, económicas y culturales, bajo sus posibilidades de las relaciones de poder desde su cuerpo, desde su intelecto y desde sus estructuras sociales dominantes, así como las de su familia, todas en el marco del pacto político y su constante actividad de legitimación.

En este horizonte el docente asume una gran responsabilidad. El docente es la bisagra entre las jóvenes generaciones y el saber-hacer en el mundo de la vida legado por los adultos desde su enciclopedia en un mundo ilustrado, en mundo-objeto de racionalizaciones en ámbitos comunicativos (con pretensiones de verdad). Ante este reto, la esencia de los modelos pedagógicos y la innovación didáctica juegan un papel trascendental en la formación de los jóvenes, en la construcción social de la realidad, a pesar de la grave crisis de las relaciones entre la academia y la sociedad, en un ámbito social ya bastante convulsionado en todas sus esferas. Este desajuste pasa por pilares esenciales como: la dificultad actual de construcción de universales morales y éticos con criterios de solidaridad y redistribución de la riqueza, por el manejo de un ser humano acorralado por las, cada vez más crecientes, exigencias de la razón en aras del disfrute de un innumerable y avasallante acopio de producción material e intelectual de bienes (mercancías casi siempre); por la pregunta bioética de una vida plena (cuya edad ya alcanza un promedio de 100 años en los países desarrollados), hecha en el disfrute tan indiscriminado como irresponsable con la naturaleza.

Así, los modelos pedagógicos deben dar cuenta de las visiones de mundo en búsqueda de soluciones, armonías y pactos sociales en aras del bien común; en la búsqueda de universales sin absolutos. Las innovaciones didácticas son el centro real del aula, del 
docente como instrumento de transmisión y construcción del saber-hacer. Desde la hermenéutica de los saberes pedagógicos los docentes, ya sea desde los textos, ya desde los debates en las unidades de enseñanza, pero, sobre todo, desde su quehacer diario, se realizan como profesionales de la educación en su lucha por construir discursos mediadores entre el saber necesario para el logro de objetivos disciplinares y el modo como estos saberes se han de lograr desde la perspectiva de quien no ha recorrido la pregunta con la repetición y rigurosidad del propio docente, de quien llega a la pregunta fragmentado y sin la experiencia debida incluso para reanudar la construcción del concepto con la premura del especialista. La didáctica es el centro real del debate educativo, desde el aula y desde la acción profesoral, pues es en esta dimensión donde se define el requerimiento y la necesidad imperiosa de la voz de los mediadores entre logros discursivos y el sujeto en formación.

En definitiva, el docente del siglo XXI no puede reducirse a un inspector de temas ni a un impartidor de calificaciones; por el contrario, la innovación didáctica debe incluir de modo crucial la pregunta por el fracaso conjunto en el proyecto de aula. Desafortunadamente, hay fallas no solo en la evaluaciones de los procesos de apropiación del conocimiento por parte de los estudiantes; sino que igualmente se incurre en graves falencias en la evaluación que los estudiantes y los directivos hacen de los docentes, casi siempre en términos de cuestiones de gusto, complacencia o incluso bajo criterios de pago-beneficio en relación con las calificaciones de estos a sus discípulos. Casi nunca las evaluaciones siguen con rigor las apuestas disciplinar y didáctica de las ofertas de los profesores. Todo esto lleva a un diálogo de sordos, permeado por un mercado darwinista de sálvese quien pueda, de un lado; o de otro lado, de atención al cliente.

Las reuniones de profesores cada vez son menos académicas; el espacio de este debate ha sido tomado por largas planeaciones sobre el presupuesto, sobre resultados estadísticos de las calificaciones (pocas veces sobre logros), sobre contratos laborales de los docentes, sin que nada de esto merezca quedar por fuera del debate; pero la esencia, el cómo de la disciplina y sus vínculos con los problemas del mundo, parece quedar en un segundo plano, por culpa de todos, dadas todas las circunstancias.

Si yo fuese decano no preguntaría a un docente solamente sobre los temas del programa, me concentraría en el cómo de sus preguntas, en el cómo de su didáctica. Un docente no gana su título por distribuir información, se es docente porque se asume la construcción de puentes entre sus viejas preguntas y el horizonte de actualidad de las mismas en aras de su comprensión por las generaciones de jóvenes en proceso de formación. La didáctica no está ni en lo enseñado ni en lo aprendido, sino en el camino diseñado por el docente para unir estas dos orillas.

Enrique Ferrer-Corredor 